\title{
REVIEW
}

\section{Is there any scientific evidence for the use of glucosamine in the management of human osteoarthritis?}

Yves Henrotin ${ }^{* 1}$, Ali Mobasheri ${ }^{2}$ and Marc Marty ${ }^{3}$

\begin{abstract}
Glucosamine in its acetylated form is a natural constituent of some glycosaminoglycans (for example, hyaluronic acid and keratan sulfate) in the proteoglycans found in articular cartilage, intervertebral disc and synovial fluid. Glucosamine can be extracted and stabilized by chemical modification and used as a drug or a nutraceutical. It has been approved for the treatment of osteoarthritis $(\mathrm{OA})$ in Europe to promote cartilage and joint health and is sold over the counter as a dietary supplement in the United States. Various formulations of glucosamine have been tested, including glucosamine sulfate and glucosamine hydrochloride. In vitro and in vivo studies have uncovered glucosamine's mechanisms of action on articular tissues (cartilage, synovial membrane and subchondral bone) and justified its efficacy by demonstrating structure-modifying and anti-inflammatory effects at high concentrations. However, results from clinical trials have raised many concerns. Pharmacokinetic studies have shown that glucosamine is easily absorbed, but the current treatment doses (for example, 1,500 mg/day) barely reach the required therapeutic concentration in plasma and tissue. The symptomatic effect size of glucosamine varies greatly depending on the formulation used and the quality of clinical trials. Importantly, the effect size reduces when evidence is accumulated chronologically and evidence for the structure-modifying effects of glucosamine are sparse. Hence, glucosamine was at first recommended by EULAR and OARSI for the management of knee pain and structure improvement in OA patients, but not in the most recent NICE guidelines. Consequently, the published recommendations for the management of $\mathrm{OA}$ require revision. Glucosamine is generally safe and although there are concerns about potential allergic and salt-related side effects of some formulations, no major adverse events have been reported so far. This paper examines all the in vitro and in vivo evidence for the mechanism of action of glucosamine as well as reviews the results of clinical trials. The pharmacokinetics, side effects and differences observed with different formulations of glucosamine and combination therapies are also considered. Finally, the importance of study design and criteria of evaluation are highlighted as new compounds represent new interesting options for the management of $O A$.
\end{abstract}

\section{Introduction}

Glucosamine is an amino sugar that is essential for the biosynthesis of glycosylated proteins and lipids. It is a major constituent of extracellular matrix macromolecules such as glycosaminoglycans (GAGs), glycolipids and glycoproteins in its acetylated form. It is present in high quantities in articular cartilage, intervertebral disc and synovial fluid [1]. Glucosamine can also be extracted

*Correspondence: yhenrotin@ulg.ac.be

'Bone and Cartilage Research Unit, University of Liège, Institute of Pathology, level 5, CHU Sart-Tilman, 4000 Liège, Belgium

Full list of author information is available at the end of the article from the chitosan and chitin exoskeleton of crustaceans such as shellfish and may be stabilized as a salt, glucosamine hydrochloride or glucosamine sulfate for oral administration. It has been used for many years in the treatment for osteoarthritis (OA). In Europe it is a registered drug approved for the treatment of OA (mainly for its symptomatic, slow acting effect in promoting cartilage and joint health). It has been designated an 'over the counter' dietary supplement by the US Food and Drug Administration.

Glucosamine was first thought to provide building blocks (substrates) for the biosynthesis of cartilage extracellular matrix. Subsequent investigations have found further explanations for its anti-inflammatory and anti-catabolic mechanisms of action. In vitro and in vivo 
Table 1. Recommendations for the use of glucosamine in the management of osteoarthritis

\begin{tabular}{|c|c|c|c|}
\hline & Reference & & Recommendation \\
\hline OARSI & {$[2,3,7]$} & & $\begin{array}{l}\text { 'Treatment with glucosamine and/or chondroitin sulphate may provide symptomatic benefit in patients with knee } \\
\text { OA. If no response is apparent within } 6 \text { months treatment should be discontinued' }\end{array}$ \\
\hline \multirow[t]{2}{*}{ EULAR } & {$[5]$} & Knee OA & $\begin{array}{l}\text { 'There is growing evidence to support the use of two of these agents for their symptomatic effects - namely, } \\
\text { glucosamine sulphate }(1 \mathrm{~A}) \text { and chondroitin sulphate }(1 \mathrm{~A}) \text {, but for the others the evidence is weak or absent' }\end{array}$ \\
\hline & {$[4]$} & Нip OA & $\begin{array}{l}\text { 'SYSADOA (glucosamine sulphate, chondroitin sulphate, diacerhein, avocado soybean unsaponifiable, and hyaluronic } \\
\text { acid) have a symptomatic effect and low toxicity, but effect sizes are small, suitable patients are not well defined, and } \\
\text { clinically relevant structure modification and pharmacoeconomic aspects are not well established' }\end{array}$ \\
\hline$A C R$ & {$[6]$} & & $\begin{array}{l}\text { 'While a number of studies support the efficacy of both glucosamine and chondroitin sulfate for palliation of joint } \\
\text { pain in patients with knee OA, the subcommittee believes that it is premature to make specific recommendations } \\
\text { about their use at this time because of methodologic considerations, including lack of standardized case definitions } \\
\text { and standardized outcome assessments, as well as insufficient information about study design in a number of these } \\
\text { published reports' }\end{array}$ \\
\hline NICE & [81] & & 'The use of glucosamine or chondroitin products is not recommended for the treatment of osteoarthritis' \\
\hline
\end{tabular}

ACR, American College of Rheumatology; EULAR, European League Against Rheumatism; NICE, National Institute for Health and Clinical Excellence; OA, osteoarthritis; OARSI, Osteoarthritis Research Society International.

studies have detailed different lines of evidence for how glucosamine can act on joint tissues from OA patients. In addition, many clinical trials have demonstrated various degrees of efficacy for glucosamine in OA patients. Based on the published data, the Osteoarthritis Research Society International (OARSI) $[2,3]$ and the European League Against Rheumatism (EULAR) [4,5] have recommended the use of glucosamine sulfate for the management of knee and hip OA. In contrast, the American College of Rheumatology (ACR) [6] and the UK National Institute for Health and Clinical Excellence (NICE) have not recommended glucosamine in the management of OA (Table 1). None of the current guidelines have recommended the use of glucosamine hydrochloride, only glucosamine sulfate. Finally, it is important to point out that OARSI recommends that treatment with glusosamine sulfate is discontinued if no symptomatic response is apparent within 6 months of use. OA recommendations are outlined in Table 1 . More recently, a change in evidence following a systematic cumulative update of research published through January 2009 has been reported by OARSI's treatment guidelines committee [7]. This meta-analysis reported a gradual decrease in the effect size (ES) when evidence from randomized controlled trials (RCTs) was chronologically evaluated. The study highlighted the controversy surrounding the efficacy of glucosamine in terms of both pain and structure modifications. The meta-analysis has highlighted the heterogeneity of outcomes in the different RCTs and the presence of publication bias. From a scientific perspective, the new concerns raised by the recent meta-analyses will undoubtedly stimulate a re-evaluation of the mechanistic effects of glucosamine.

The use of glucosamine in the management of OA remains controversial and its specific mechanism of action in OA pain and function modification are still unclear. The objective of this review is to address the question raised in the title: is glucosamine still an option in the management of OA? This review summarizes the effects of glucosamine in OA based on in vitro and in vivo results as well as recent clinical trials. Special attention is given to the pharmacokinetics of glucosamine, its side effects and the differences observed with different formulations and combination therapies. Finally, based on these observations, a conclusion is drawn on the role of glucosamine in the management of OA in the context of new compounds and new combinations.

\section{Update on in vitro data}

The anabolic effects of glucosamine were primarily thought to be attributable to its capacity for providing building blocks for the synthesis of GAGs by chondrocytes [8-10]. Other effects have also been reported, however, such as its anti-catabolic potency, seen by its inhibition of the expression and/or activity of catabolic enzymes such as phospholipase $\mathrm{A}_{2}$, matrix metalloproteinases or aggrecanases $[11,12]$. Another study confirmed the potency of glucosamine to inhibit the expression and activity of aggrecanase-2 (a disintegrin and metalloproteinase with thrombospondin motifs 5 (ADAMTS-5)) in transiently transfected cell lines [13]. The authors suggested that the symptomatic and functional effects of glucosamine would be justified by the fact that glucosamine interferes with the matrix metalloproteinases responsible for proteoglycan degradation in OA.

Various properties were demonstrated for glucosamine in the three main tissues involved in OA, cartilage, synovial membrane and subchondral bone. The main potencies were shown in articular chondrocytes, where glucosamine was demonstrated to reverse the deleterious effects of IL-1 $\beta[11,14,15]$. In rat and human chondrocytes, the glucosamine effect was shown to occur through the inhibition of NF- $\mathrm{kB}$ signaling $[16,17]$. The reversal of the effects of IL- $1 \beta$ in human chondrocytes also inhibited 
inflammatory enzymes, such as the inducible form of nitric oxide synthase and cyclooxygenase-2 [18]. This effect of glucosamine was further detailed by Imagawa and co-workers [19], who were able to demonstrate that glucosamine prevents the demethylation of specific $\mathrm{CpG}$ sites in the IL- $1 \beta$ promoter, consequently preventing the expression of IL- $1 \beta$.

A recent pharmacoproteomic study revealed that glucosamine $(10 \mathrm{mM})$ differentially regulates the pattern of expression of IL-1 $\beta$-induced proteins in human articular chondrocytes [20]. The proteins affected by glucosamine are mainly involved in the signal transduction pathways, redox and stress response, protein synthesis and protein folding. In addition, glucosamine increased the expression of the GRP78 chaperone protein. This observation supports the reported antiinflammatory effect of glucosamine. This study also compared glucosamine to chondroitin sulfate; these compounds produced different patterns of protein modification when tested alone or in combination [20]. A synergistic effect for the modification of superoxide dismutase expression was demonstrated when cells were exposed to both compounds, implying a potent effect on oxidative stress in addition to the modulation of energy production and metabolic pathways produced by chondroitin sulfate.

The pro-anabolic effects of glucosamine were demonstrated in both human chondrocytes and synovial cells, where glucosamine was shown to induce the production of hyaluronic acid (HA) and to directly enter the GAG biosynthetic pathway (that is, for the production of HA, keratan sulfate and sulfated GAGs) [21]. The authors also proposed that the chondroprotective effect of glucosamine results from the modulation of enzymes responsible for HA synthesis.

The potential of glucosamine to induce HA production in the synovial membrane was previously suggested in a study that used synovial explants [22]. In addition, cationic glucosamine derivatives were shown to produce an anti-inflammatory effect through the inhibition of mitogen-activated protein kinase signaling pathways in lipopolysaccharide-stimulated macrophages [23].

Glucosamine sulfate was also shown to be effective in human OA osteoblasts [24]. Glucosamine increased the osteoprotegrin/receptor activator of nuclear factor kappa-B ligand (RANKL) ratio and reduced bone resorption. This effect was increased when glucosamine was used in combination with chondroitin sulfate.

It is important to point out that these studies were performed in different culture systems, with various formulations and concentrations of glucosamine. The details of the culture systems and the formulations are provided in Table 2. The concentrations used in the in vitro studies were 'super physiological' - in some cases up to 2,000 times higher than the maximal concentration that can realistically be achieved in plasma $(10 \mu \mathrm{M})$ after oral administration of $1,500 \mathrm{mg}$ of glucosamine sulfate in human subjects. Furthermore, some of these studies compared the effects of two formulations of glucosamine in order to provide evidence for the superiority of one or another $[21,22,25,26]$. It was proposed that the differences, if they truly existed, might contribute to the different results observed in clinical trials with various glucosamine formulations. For example, glucosamine sulfate was shown to be a stronger inhibitor of gene expression than glucosamine hydrochloride [25]. Both formulations were commercially available from a lab supplier. The same group compared glucosamine hydrochloride to $\mathrm{N}$-acetylglucosamine [22] and observed no effect of $\mathrm{N}$-acetylglucosamine on HA production whereas glucosamine hydrochloride appeared to modulate this parameter. The same conclusion was reached in the study by Igarashi and colleagues [21]. In contrast, another study compared the effect of native glucosamine and $\mathrm{N}$ acetylglucosamine on the metabolic activity of human articular chondrocytes [26]. Both compounds exhibited different potencies on glucose transport, and GAG and HA synthesis. Indeed, $\mathrm{N}$-acetylglucosamine appeared to accelerate the facilitated glucose uptake and increase both GAG and HA synthesis, suggesting that $\mathrm{N}$-acetylglucosamine may be more efficient than native glucosamine.

Glucosamine has also been tested in combination with chondroitin sulfate in vitro. Some of the results have already been discussed above [20,24]. The effect of combinations of glucosamine and chondroitin was also reported by Chan and colleagues [27-30]. Glucosamine hydrochloride was tested in combination with chondroitin sulfate on bovine cartilage explants. The combination was shown to inhibit both inflammatory and catabolic intermediates and was slightly superior to glucosamine alone $[27,28]$.

Finally, some authors have studied the contribution of exogenous glucosamine to the synthesis of chondroitin sulfate in human articular chondrocytes in culture [31]. They concluded that exogenous glucosamine cannot stimulate the synthesis of chondroitin sulfate. Furthermore, they showed that glucose can increase endogenous glucosamine to reach concentrations superior to those achieved after oral administration.

In conclusion, many of the in vitro investigations carried out so far have been performed using high concentrations of glucosamine - concentrations that are unlikely to be achieved in plasma with oral doses of the drug. Several authors have proposed that the therapeutic doses used did not allow the identification of proteoglycan synthesis as a mechanism of action of glucosamine $[31,32]$. Therefore, extrapolation of the in vitro data to the in vivo situation should be done with great caution. 
Table 2. Principal characteristics of the in vitro studies testing glucosamine

\begin{tabular}{|c|c|c|c|}
\hline Model & Concentration & Results & Reference \\
\hline \multicolumn{4}{|l|}{ Glucosamine sulfate } \\
\hline Human OA chondrocytes & $5-500 \mu \mathrm{M}$ & Inhibition of PLA ${ }_{2}$ and collagenase in a lesser extent through PKC inhibition & [12] \\
\hline $\begin{array}{l}\text { Human } O A \text { chondrocytes stimulated } \\
\text { with IL-1 } \beta\end{array}$ & $10-1,000 \mathrm{mg} / \mathrm{L}$ & $\begin{array}{l}\text { Inhibition of NF-KB activation } \\
\text { Inhibition of COX-2 expression and synthesis and } \mathrm{PGE}_{2} \text { release }\end{array}$ & [17] \\
\hline $\begin{array}{l}\text { Human chondrocytes stimulated } \\
\text { with IL-1 } 1 \beta\end{array}$ & $10 \mathrm{mM}$ & Influence of the proteomic profile & [20] \\
\hline Human OA cartilage explants & $5 \mathrm{mM}$ & $\begin{array}{l}\text { Inhibition of catabolic and anabolic gene expression } \\
\text { Superiority over glucosamine hydrochloride in the same conditions }\end{array}$ & [25] \\
\hline Human OA osteoblasts & $200 \mu \mathrm{g} / \mathrm{ml}$ & Inhibition of pro-resorptive agents & [24] \\
\hline \multicolumn{4}{|l|}{ Glucosamine hydrochloride } \\
\hline Transfected cell lines & $10 \mathrm{mM}$ & Inhibition of ADAMTS-5 expression and activity & [13] \\
\hline Human OA synovium explants & $0.5-5 \mathrm{mM}$ & $\begin{array}{l}\text { Induction of } \mathrm{HA} \text { production } \\
\text { No effect of } \mathrm{N} \text {-acetylglucosamine }\end{array}$ & [22] \\
\hline \multicolumn{4}{|l|}{$\mathrm{D}(+)$-Glucosamine } \\
\hline $\begin{array}{l}\text { Rat chondrosarcoma cell line and } \\
\text { bovine cartilage explants }\end{array}$ & 2-16 mM & Inhibition of aggrecanase-dependent cleavage & [11] \\
\hline Rat chondrocytes stimulated with IL-1 $\beta$ & $1-4.5 \mathrm{~g} / \mathrm{L}$ & Reversion of IL-1 $\beta$ deleterious effect on PG anabolism & [14] \\
\hline Rat chondrocytes stimulated with IL-1 $\beta$ & $4.5 \mathrm{~g} / \mathrm{L}$ & Inhibition of NF-KB & [16] \\
\hline Rat chondrocytes stimulated with IL-1 $\beta$ & $20 \mathrm{mM}$ & $\begin{array}{l}\text { Inhibition of inflammatory cytokines, chemokines and growth factors } \\
\text { Inhibition of MMPs and aggrecanase-1 }\end{array}$ & {$[15]$} \\
\hline $\begin{array}{l}\text { Human synovial cells and } \\
\text { chondrocytes }\end{array}$ & $0.1-1.0 \mathrm{mM}$ & $\begin{array}{l}\text { Stimulation of HA and GAG production } \\
\text { Stimulation of HA synthase activity } \\
\text { No effect of } \mathrm{N} \text {-acetylglucosamine }\end{array}$ & [21] \\
\hline \multicolumn{4}{|l|}{$\mathrm{N}$-acetylglucosamine } \\
\hline $\begin{array}{l}\text { Human chondrocytes stimulated } \\
\text { with IL-1 } \beta\end{array}$ & $10 \mathrm{mM}$ & Inhibition of iNOS, COX-2 and IL-6 expression & [18] \\
\hline Human chondrocytes & 5-20 mM & $\begin{array}{l}\text { Increased synthesis of GAG and HA due to acceleration of facilitated } \\
\text { glucose uptake } \\
\text { Superiority over native glucosamine }\end{array}$ & [26] \\
\hline $\begin{array}{l}\text { Human chondrocytes (normal and } \\
\text { OA) stimulated with IL-1 } \beta\end{array}$ & $2 \mathrm{mM}$ & $\begin{array}{l}\text { Prevention of the cytokine-induced demethylation of } C p G \text { site in the IL-1 } \beta \\
\text { promoter resulting in decreased expression of } I L-1 \beta\end{array}$ & [19] \\
\hline
\end{tabular}

ADAMTS-5, a disintegrin and metalloproteinase with thrombospondin motifs 5; COX-2, cyclooxygenase-2; GAG, glycosaminoglycan; HA, hyaluronic acid; iNOS, inducible nitric oxide synthase; MMP, matrix metalloproteinase; $\mathrm{OA}$, osteoarthritis; $\mathrm{PG}$, proteoglycan; $\mathrm{PKC}$, protein kinase $\mathrm{C}_{;} \mathrm{PGE}_{2^{\prime}}$, prostaglandin $\mathrm{E}_{2^{\prime}}$; $\mathrm{PLA}_{2^{\prime}}$ phospholipase $\mathrm{A}_{2}$.

\section{Update on in vivo data}

Several recent in vivo studies using different animal models have demonstrated varying potencies for glucosamine in OA. Glucosamine sulfate (200 and $400 \mathrm{mg} / \mathrm{kg} /$ day) was tested in the STR/ort mouse model of spontaneous OA [33]. Glucosamine was shown to delay the progression and severity of OA cartilage lesions. Another study reported the effect of glucosamine sulfate $(250 \mathrm{mg} / \mathrm{kg} /$ day) administered to rats after anterior cruciate ligament transection (ACLT) [34]. The glucosamine treatment group showed a lower level of cartilage degradation and synovial inflammation compared to the control group. Glucosamine was also shown to modify nociception in $\mathrm{OA}$ rats. Mechanical allodynia and weight-bearing distribution were significantly improved by the treatment with glucosamine. In addition, the authors showed that glucosamine affected mitogen-activated protein kinase signaling in articular chondrocytes by inhibiting p38 and JNK expression while increasing Erk1/2 expression.

The effect of glucosamine on cartilage degradation, synovial inflammation and bone resorption was recently tested in a model of collagenase-induced OA [35]. This study also compared the efficacies of glucosamine hydrochloride and glucosamine sulfate. The authors showed a better efficacy for glucosamine hydrochloride but did not provide any explanation for this difference. Indeed, glucosamine sulfate demonstrated no effect on the histological score and the formation of osteophytes whereas glucosamine hydrochloride produced a significant reduction of these parameters; glucosamine sulfate was not further evaluated. However, the results showed that glucosamine hydrochloride administered orally to OA mice $(20 \mathrm{mg} / \mathrm{kg} /$ day) inhibited not only the loss of GAGs and proteoglycans in articular cartilage but also 
bone resorption by the inhibition of RANKL through downregulation of bone morphogenic protein-2, transforming growth factor- $\beta 3$ and pSMAD2 and the upregulation of Dickkopf-1 protein levels in the joint. In the same study, glucosamine hydrochloride also reduced osteophyte formation and was shown to inhibit the production of the pro-inflammatory cytokine IL-6 and to upregulate the production of the anti-inflammatory cytokine IL-10 by the synovial membrane.

Glucosamine hydrochloride was also tested in the rat ACLT model of OA [36]. Glucosamine administered at a dose of $1,000 \mathrm{mg} / \mathrm{kg} /$ day produced a chondroprotective effect and reduced the serum level of the collagen degradation biomarker CTX-II. It was also tested on equine synovial inflammation induced by lipopolysaccharide injection [37]. Glucosamine hydrochloride was administered by nasogastric gavage at a dose of $20 \mathrm{mg} / \mathrm{kg}$. This study revealed that glucosamine levels were increased in the synovium during inflammation in comparison to the healthy joint. The authors did not conclude if glucosamine produced a therapeutic effect or not. The same group has previously published results comparing the pharmacokinetics of glucosamine sulfate to glucosamine hydrochloride in horses [38]. They measured higher concentrations of glucosamine in synovial fluid after glucosamine sulfate administration than after glucosamine hydrochloride administration and concluded that glucosamine sulfate is better absorbed by the horse. Glucosamine hydrochloride was also tested in OA dogs in combination with chondroitin sulfate [39]. The combination of the two compounds reduced pain and improved weight bearing as well as reduced disease progression.

Glucosamine in the form of $\mathrm{N}$-acetylglucosamine was tested in rabbits undergoing the ACLT model of OA [40]. $\mathrm{N}$-acetylglucosamine was administered once a week intraarticularly at a dose of $150 \mathrm{mg} /$ injection. This study suggested that glucosamine may preserve the integrity of articular cartilage but no statistical evidence was provided to support this suggestion.

Finally, glucosamine sulfate $(500 \mathrm{mg} / \mathrm{kg})$ and a combination of it with chondroitin sulfate $(400 \mathrm{mg} / \mathrm{kg})$ were compared in the rat ACLT model of OA [41]. The results showed the superiority of the combination over glucosamine alone in the prevention of biochemical and histological cartilage modifications that occur in the rat OA model.

Glucosamine has produced various effects in different in vivo models. It has been tested under different conditions with different formulations and dosages, tending to produce a protective effect on articular tissues. At this stage it is impossible to conclude whether one formulation is superior to another. Therefore, further studies are clearly warranted.

\section{Clinical data}

\section{Pharmacokinetic studies}

The pharmacokinetics of exogenous glucosamine has been difficult to study since glucosamine is naturally present in several biological fluids. The origin of endogenous glucosamine, if any, is unknown, although it could be speculated that endogenous glucosamine mainly results from connective tissue metabolism, since glucosamine is contained in tissues that are not consumed (for example, shellfish exoskeleton). Analytical methods have been developed in order to measure glucosamine in human plasma [42-44] and synovial fluid [45]. Most of the available data on the pharmacokinetics of glucosamine have been obtained with glucosamine sulfate; few studies have been published on the pharmacokinetics of glucosamine hydrochloride in human subjects.

The first pharmacokinetic study of glucosamine sulfate was done in 12 healthy volunteers ( 6 females and 6 males) after repeated oral doses [46]. Glucosamine was rapidly absorbed and available in the systemic circulation. It reached steady state after 3 hours and the maximal plasma concentration was $10 \mu \mathrm{M}$ after oral intake of a standard dose of $1,500 \mathrm{mg}$. The plasma concentration was shown to remain above baseline for up to 48 hours after oral administration. The elimination half-life was estimated at 15 hours, on the basis of a single oral daily dose. Pharmacokinetics were further investigated in $12 \mathrm{OA}$ patients with the same regimen of administration [47]. This study revealed that glucosamine was bioavailable both in plasma and at the site of action, that is, within the joint. Glucosamine reached constant and higher levels (up to $25 \%$ higher) in the synovial fluid compared to plasma. Selective accumulation was also observed in cartilage after repeated administration of glucosamine [48]. Glucosamine was found not to bind to plasma proteins and up to 43 to $47 \%$ was associated with blood cells [49]. The authors concluded that the pharmacologically active fraction of glucosamine was the same in plasma and at the site of action.

Some information regarding the pharmacokinetics of glucosamine hydrochloride has been recently published [50]. The main purpose of this work was to study the influence of glucosamine on the pharmacokinetics of chondroitin sulfate, although this study did provide a few pharmacokinetic parameters for glucosamine hydrochloride. The authors showed that a single oral administration of $1,500 \mathrm{mg}$ led to a maximal plasma concentration of $492 \pm 161 \mathrm{ng} / \mathrm{ml}\left(2.28 \mu \mathrm{M} ; \mathrm{C}_{\max }\right)$ reached in $2.31 \pm 1.19 \mathrm{~h}\left(\mathrm{~T}_{\max }\right)$. After 3 months of multiple dosing, $\mathrm{C}_{\max }$ was reduced to $211 \pm 93.1 \mathrm{ng} / \mathrm{ml}(0.98 \mu \mathrm{M})$ and $\mathrm{T}_{\max }$ was identical at $2.31 \pm 1.19 \mathrm{~h}$. In addition, glucosamine hydrochloride in combination with chondroitin sulfate showed a lower plasmatic level, meaning that chondroitin 
sulfate inhibits glucosamine hydrochloride absorption and decreases its biodisponibility [50].

Glucosamine hydrochloride and sulfate are identical from a chemical and structural point of view. The addition of salt does not justify the difference in efficacy or biological effects observed in different studies. Indeed, both glucosamine sulfate and hydrochloride dissociate in the acidic milieu of the stomach, resulting in the release of glucosamine itself [51]. It is important to bear in mind that the pharmacokinetic parameters were determined in two different systems (administration and analytical methods), which could explain the observed differences. To date, no published study has directly compared the two formulations and/or established a rigorous methodology for comparison.

\section{Clinical efficacy}

Glucosamine is classically administered orally to human subjects at a dose of $1,500 \mathrm{mg} /$ day. In clinical trials involving OA patients it was shown to reduce pain and provide functional improvement [52-54] in addition to structure-modifying effects [55,56]. Several metaanalyses have summarized the efficacy of glucosamine as reported from different clinical trials [52,54,57-59]. The most recent study from Wandel and colleagues [60] analyzed the results from randomized trials with an average of at least 100 patients with hip or knee OA. The authors searched databases through to June 2010, including the most recent trials [61-64]. They retrieved a total of 10 trials (a total of 3,803 patients) that met their inclusion criteria. Their analysis reported ESs of -0.17 $(-0.28$ to -0.05$)$ for joint pain and $-0.16(-0.25$ to 0.00$)$ for joint space width with glucosamine. They concluded that glucosamine produced no clinically relevant effect on pain or structure. Another recent meta-analysis concentrated on the structure-modifying effect of glucosamine [65]. The authors searched databases through 2008. They retrieved two trials meeting their criteria with glucosamine and structural modifications in OA patients. Their analysis of joint space narrowing and odds ratios revealed that glucosamine sulfate was not effective at producing structural modifications after one year of treatment, but glucosamine sulfate produced a small to moderate protective effect on minimum joint space narrowing after three years. It is important to note that this analysis was performed using just two trials.

The systematic review that is the basis for OARSI recommendations for the management of hip and knee OA was recently updated using more recent publications on glucosamine (until January 2009) [7] and highlighted many interesting points. The analysis gathered the results from 19 RCTs from a total of 20 retrieved placebocontrolled trials, including the recent ones already mentioned above. Sixteen of them used glucosamine sulfate preparations (thirteen oral, two intra-muscular and one intra-articular) and three of them used glucosamine hydrochloride. This review revealed a decrease of ES for pain evaluated without discrimination between glucosamine preparations from 0.61 (0.28 to 0.95$)$ in 2008 [3] to 0.46 (0.23 to 0.69$)$ in 2010 , corresponding to a moderate symptomatic efficacy [7]. The ES for pain reduction was 0.58 (0.30 to 0.87 ) for glucosamine sulfate, whereas it was not significant for glucosamine hydrochloride $(-0.02$ $(-0.15$ to 0.11$))$. However, the analysis revealed that the outcomes of trials conducted with glucosamine hydrochloride were homogenous, while those conducted with glucosamine sulfate were very heterogeneous. When considering only high quality trials, the ES for glucosamine sulfate decreased to 0.29 (0.003 to 0.57 ), with no publication bias but still heterogeneity outcomes of trials. The same analysis revealed a small but significant ES (0.24 (0.04 to 0.43$))$ for glucosamine sulfate for reduction of joint space loss in the medial compartment of knee OA patients, as reported by two sponsored RCTs $[55,56]$, but a non-significant effect on joint space narrowing in hip OA patients after a 24-month treatment either when considering the whole study group [66] or when analyzing predefined subgroups for OA severity [64]. The same conclusion was reached by the Glucosamine/Chondroitin Arthritis Intervention Trial (GAIT), with a ES of 0.15 (-0.07 to 0.38 [61]. In addition, this trial did not validate the conclusion of a study by Bruyere and colleagues [67] that glucosamine sulfate $(1,500 \mathrm{mg} /$ day $)$ taken for at least 12 months reduces by half the incidence of total knee replacement, since the decision for surgical intervention is influenced by many factors. The structure-modifying effect of glucosamine on OA joints remains controversial.

Two clinical trials have been published since the publications of these meta-analyses. The results of the first one by Sawitzke and colleagues [68] were in line with the previously mentioned analysis and reported no significant difference in the Western Ontario and McMaster Universities Osteoarthritis Index (WOMAC) pain or function score with glucosamine compared to placebo. The second one by Petersen and colleagues [69] studied a different outcome: the serum level of cartilage oligomeric matrix protein, a marker of cartilage degradation. This studied showed that combined with exercise, glucosamine sulfate treatment reduced the level of serum cartilage oligomeric matrix protein.

Meta-analyses have revealed the heterogeneity of outcome measures and the presence of publication bias $[2,3,7]$. The most recent analysis by Wandel and colleagues [60] confirms this. The analysis reported that the estimated differences between placebo and studied supplements were less pronounced in industry-independent trials compared to industry-sponsored trials. However, the retrieved trials in this analysis demonstrated less 
heterogeneity. The quality of clinical trials, including study design, number of patients, outcome measures and publication bias, justified the drastic reduction of the ES observed for glucosamine over the years and trials.

Finally, the weak effect of glucosamine reported by clinical trials can be attributed to the low concentrations of glucosamine available to joint tissues [51]. Indeed, the competition that exists between glucosamine and glucose for cellular uptake favors transport of glucosamine in the intestine, liver and kidney, leaving little glucosamine available for uptake by the joint.

\section{Side effects}

Glucosamine is considered to be safe, and no serious or fatal adverse events have ever been reported from RCTs. However, several potential side effects have to be kept in mind. The first and most evident side effect of glucosamine that patients should be aware of is shellfish allergy. Indeed, glucosamine is extracted from chitin contained in shellfish and could lead to allergic reactions in certain individuals. In addition, glucosamine sulfate is administered as a salt, combined with $\mathrm{NaCl}$. This formulation provides up to $30 \%$ of the daily intake of salt. This matter has to be taken into account since $\mathrm{Na}^{+}$but also $\mathrm{Cl}^{-}$could influence blood pressure and renal function in patients $[70,71]$. Finally, some human and animal studies have suggested that glucosamine can affect glucose metabolism and it has been shown to induce insulin resistance [72-75]. Despite the evidence, however, a recent comprehensive review supported by a glucosamine manufacturer has rejected these statements. The authors concluded that glucosamine had no effect on fasting blood glucose levels, glucose metabolism, or insulin sensitivity at any oral dose level in healthy subjects, individuals with diabetes, or those with impaired glucose metabolism [76]. The lack of reported adverse events during clinical trials could be attributable to the short duration of patient exposure to the treatment. Therefore, long-term treatment could be risky for diabetic and/or hypertensive patients. For these reasons, many authors recommend to monitor blood glucose concentration and blood pressure in these patients [73-75,77]. Clearly, further studies are warranted to determine the longer term effects of glucosamine on insulin sensitivity in human subjects.

\section{Conclusion}

Different formulations of glucosamine tested in various in vitro or in vivo systems have exhibited many potential mechanisms of action on articular structures. Furthermore, two of the major published guidelines recommended glucosamine sulfate in the treatment of OA pain while another integrating more recent data did not consider glucosamine sulfate. At this time, glucosamine hydrochloride cannot be recommended based on the available clinical data. However, there are no clear indications that the effects of the two formulations can be distinguished from each other in terms of biological activity, posology or pharmacokinetics. Recent metaanalyses have reminded us of the importance of the quality of the clinical trials and this matter is more and more frequently addressed in the literature [51]. The evaluation tools and the design of clinical trials should be standardized and there are many ongoing efforts in this area [78].

Finally, it is important to note that the majority of the published clinical trials with glucosamine reported a significant ratio of subjects who failed to respond to treatment. Therefore, the question of the benefit of glucosamine treatment remains largely unanswered. One may wonder about the clinical relevance of this treatment and whether to use it with regards to the cost/benefit ratio. On the one hand, compared to non-pharmacological modalities such as exercise, weight loss or education, glucosamine is not effective with regards to pain and function, but the question of its cost compared to nonpharmacological modalities should be explored. On the other hand, glucosamine sulfate shows an ES superior to (or at least equal to) the commonly used analgesic or nonsteroidal anti-inflammatory drugs, but has no rare or adverse effects.

Therefore, based on the fact that glucosamine has low and rare adverse effects, it represents a viable option for the management of OA (as a symptomatic slow acting drug) but its administration should be discontinued if no significant effect is reported by the patient. New tools, such as novel biomarkers, are required to discriminate responders and non-responders. The use of glucosamine associated with the monitoring of response using an appropriate biomarker could improve the efficiency and the cost/benefit ratio of the treatment. Finally, we should consider the use of glucosamine as a combination therapy with other drugs or other nutraceuticals, such as omega-3 fatty acid or manganese ascorbate $[79,80]$. This would open up a new horizon in this field but the combinations would need to be rigorously assessed.

\section{Abbreviations}

ACLT, anterior cruciate ligament transection; ES, effect size; EULAR, European League Against Osteoarthritis; GAG, glycosaminoglycan; HA, hyaluronic acid; IL, interleukin; NF, nuclear factor; OA, osteoarthritis; OARSI, Osteoarthritis Research Society International; RANKL, receptor activator of nuclear factor kappa-B ligand; RCT, randomized controlled trial.

\section{Acknowledgements}

The authors would like to thank Christelle Boileau for her kind assistance with the writing and editing of this paper.

\section{Competing interests}

$\mathrm{YH}$ has received consulting fees and educational grants from companies developing nutraceuticals, food supplements or drugs for the treatment of osteoarthritis (Nestlé, Tilman SA, Bioiberica, Pierre fabre, Merck). YH is the 
founder of Artialis, a spin-off company of the University of Liège specialized in the development and commercialization of in vitro diagnostic kits. MM and MA have no competing interests.

\section{Author details}

'Bone and Cartilage Research Unit, University of Liège, Institute of Pathology, level 5, CHU Sart-Tilman, 4000 Liège, Belgium. ${ }^{2}$ School of Veterinary Medicine and Science, Faculty of Medicine and Health Sciences, University of Nottingham, Sutton Bonington Campus, Leicestershire, LE12 5RD, United Kingdom. ${ }^{3}$ Department of Rheumatology, Henri Mondor Hospital, Creteil, France.

\section{Published: 30 January 2012}

\section{References}

1. Hamerman D: The biology of osteoarthritis. N Engl J Med 1989, 320:1322-1330.

2. Zhang W, Moskowitz RW, Nuki G, Abramson S, Altman RD, Arden N, BiermaZeinstra S, Brandt KD, Croft P, Doherty M, Dougados M, Hochberg M, Hunter DJ, Kwoh K, Lohmander LS, Tugwell P: OARSI recommendations for the management of hip and knee osteoarthritis, Part I: Critical appraisal of existing treatment guidelines and systematic review of current research evidence. Osteoarthritis Cartilage 2007, 15:981-1000.

3. Zhang W, Moskowitz RW, Nuki G, Abramson S, Altman RD, Arden N, BiermaZeinstra S, Brandt KD, Croft P, Doherty M, Dougados M, Hochberg M, Hunter DJ, Kwoh K, Lohmander LS, Tugwell P: OARSI recommendations for the management of hip and knee osteoarthritis, Part II: OARSI evidencebased, expert consensus guidelines. Osteoarthritis Cartilage 2008, 16:137-162.

4. Zhang W, Doherty M, Arden N, Bannwarth B, Bijlsma J, Gunther KP, Hauselmann HJ, Herrero-Beaumont G, Jordan K, Kaklamanis P, Leeb B, Lequesne M, Lohmander S, Mazieres B, Martin-Mola E, Pavelka K, Pendleton A, Punzi L, Swoboda B, Varatojo R, Verbruggen G, Zimmermann-Gorska I, Dougados M; EULAR Standing Committee for International Clinical Studies Including Therapeutics (ESCISIT): EULAR evidence based recommendations for the management of hip osteoarthritis: report of a task force of the EULAR Standing Committee for International Clinical Studies Including Therapeutics (ESCISIT). Ann Rheum Dis 2005, 64:669-681.

5. Jordan KM, Arden NK, Doherty M, Bannwarth B, Bijlsma JW, Dieppe P, Gunther K, Hauselmann H, Herrero-Beaumont G, Kaklamanis P, Lohmander S, Leeb B, Lequesne M, Mazieres B, Martin-Mola E, Pavelka K, Pendleton A, Punzi L, Serni U, Swoboda B, Verbruggen G, Zimmerman-Gorska I, Dougados M; Standing Committee for International Clinical Studies Including Therapeutic Trials ESCISIT: EULAR Recommendations 2003: an evidence based approach to the management of knee osteoarthritis: Report of a Task Force of the Standing Committee for International Clinical Studies Including Therapeutic Trials (ESCISIT). Ann Rheum Dis 2003, 62:1145-1155.

6. American College of Rheumatology Subcommittee on Osteoarthritis G: Recommendations for the medical management of osteoarthritis of the hip and knee: 2000 update. Arthritis Rheum 2000, 43:1905-1915.

7. Zhang W, Nuki G, Moskowitz RW, Abramson S, Altman RD, Arden NK, BiermaZeinstra S, Brandt KD, Croft P, Doherty M, Dougados M, Hochberg M, Hunter DJ, Kwoh K, Lohmander LS, Tugwell P: OARSI recommendations for the management of hip and knee osteoarthritis: Part III: changes in evidence following systematic cumulative update of research published through January 2009. Osteoarthritis Cartilage 2010, 18:476-499.

8. Bassleer C, Rovati L, Franchimont P: Stimulation of proteoglycan production by glucosamine sulfate in chondrocytes isolated from human osteoarthritic articular cartilage in vitro. Osteoarthritis Cartilage 1998, 6:427-434.

9. Bassleer $C$, Henrotin $Y$, Franchimont $P$ : In vitro evaluation of drugs proposed as chondroprotective agents. Int J Tissue React 1992, 14:231-241.

10. Noyszewski EA, Wroblewski K, Dodge GR, Kudchodkar S, Beers J, Sarma AV, Reddy R: Preferential incorporation of glucosamine into the galactosamine moieties of chondroitin sulfates in articular cartilage explants. Arthritis Rheum 2001, 44:1089-1095.

11. Sandy JD, Gamett D, Thompson V, Verscharen C: Chondrocyte-mediated catabolism of aggrecan: aggrecanase-dependent cleavage induced by interleukin-1 or retinoic acid can be inhibited by glucosamine. Biochem $J$ 1998, 335:59-66.

12. Piperno M, Reboul P, Hellio Le Graverand MP, Peschard MJ, Annefeld M,
Richard M, Vignon E: Glucosamine sulfate modulates dysregulated activities of human osteoarthritic chondrocytes in vitro. Osteoarthritis Cartilage 2000, 8:207-212

13. McCulloch DR, Wylie JD, Longpre JM, Leduc R, Apte SS: 10 mM glucosamine prevents activation of proADAMTS5 (aggrecanase-2) in transfected cells by interference with post-translational modification of furin. Osteoarthritis Cartilage 2010, 18:455-463.

14. Gouze JN, Bordji K, Gulberti S, Terlain B, Netter P, Magdalou J, Fournel-Gigleux $S$, Ouzzine M: Interleukin-1 beta down-regulates the expression of glucuronosyltransferase I, a key enzyme priming glycosaminoglycan biosynthesis: influence of glucosamine on interleukin-1 beta-mediated effects in rat chondrocytes. Arthritis Rheum 2001, 44:351-360.

15. Gouze JN, Gouze E, Popp MP, Bush ML, Dacanay EA, Kay JD, Levings PP, Patel KR, Saran JP, Watson RS, Ghivizzani SC: Exogenous glucosamine globally protects chondrocytes from the arthritogenic effects of IL-1 beta. Arthritis Res Ther 2006, 8:R173.

16. Gouze JN, Bianchi A, Becuwe P, Dauca M, Netter P, Magdalou J, Terlain B, Bordji K: Glucosamine modulates IL-1-induced activation of rat chondrocytes at a receptor level, and by inhibiting the NF-kappa B pathway. FEBS Lett 2002, 510:166-170.

17. Largo R, Alvarez-Soria MA, Diez-Ortego I, Calvo E, Sanchez-Pernaute O, Egido J, Herrero-Beaumont G: Glucosamine inhibits IL-1 beta-induced NFkappaB activation in human osteoarthritic chondrocytes. Osteoarthritis Cartilage 2003, 11:290-298.

18. Shikhman AR, Kuhn K, Alaaeddine N, Lotz M: N-acetylglucosamine prevents IL-1 beta-mediated activation of human chondrocytes. J /mmuno/ 2001, 166:5155-5160.

19. Imagawa K, de Andres MC, Hashimoto K, Pitt D, Itoi E, Goldring MB, Roach HI Oreffo RO: The epigenetic effect of glucosamine and a nuclear factorkappa B (NF-kB) inhibitor on primary human chondrocytes--implications for osteoarthritis. Biochem Biophys Res Commun 2011, 405:362-367.

20. Calamia V, Ruiz-Romero C, Rocha B, Fernandez-Puente P, Mateos J, Montell E, Verges J, Blanco F: Pharmacoproteomic study of the effects of chondroitin and glucosamine sulfate on human articular chondrocytes. Arthritis Res Ther 2010, 12:R138.

21. Igarashi M, Kaga I, Takamori Y, Sakamoto K, Miyazawa K, Nagaoka I: Effects of glucosamine derivatives and uronic acids on the production of glycosaminoglycans by human synovial cells and chondrocytes. Int J Mol Med 2011, 27:821-827.

22. Uitterlinden EJ, Koevoet JL, Verkoelen CF, Bierma-Zeinstra SM, Jahr H, Weinans $H$, Verhaar JA, van Osch GJ: Glucosamine increases hyaluronic acid production in human osteoarthritic synovium explants. BMC Musculoskelet Disord 2008, 9:120.

23. Mendis E, Kim M-M, Rajapakse N, Kim S-K: Suppression of cytokine production in lipopolysaccharide-stimulated mouse macrophages by novel cationic glucosamine derivative involves down-regulation of NF-[kappa]B and MAPK expressions. Bioorganic Med Chem 2008, 16:8390-8396.

24. Tat SK, Pelletier JP, Vergés J, Montell E, Lajeunesse D, Fahmi H, Lavigne M, Martel-Pelletier J: Chondroitin and glucosamine sulfate in combination decrease the pro-resorptive properties of human osteoarthritis subchondral bone osteoblasts. Arthritis Res Ther 2007, 9:R117.

25. Uitterlinden EJ, Jahr $\mathrm{H}$, Koevoet JL, Jenniskens YM, Bierma-Zeinstra SM, Degroot J, Verhaar JA, Weinans H, van Osch GJ: Glucosamine decreases expression of anabolic and catabolic genes in human osteoarthritic cartilage explants. Osteoarthritis Cartilage 2006, 14:250-257.

26. Shikhman AR, Brinson DC, Valbracht J, Lotz MK: Differential metabolic effects of glucosamine and $\mathrm{N}$-acetylglucosamine in human articular chondrocytes. Osteoarthritis and Cartilage 2009, 17:1022-1028.

27. Chan PS, Caron JP, Rosa GJ, Orth MW: Glucosamine and chondroitin sulfate regulate gene expression and synthesis of nitric oxide and prostaglandin $E(2)$ in articular cartilage explants. Osteoarthritis Cartilage 2005, 13:387-394.

28. Chan PS, Caron JP, Orth MW: Effect of glucosamine and chondroitin sulfate on regulation of gene expression of proteolytic enzymes and their inhibitors in interleukin-1-challenged bovine articular cartilage explants. Am J Vet Res 2005, 66:1870-1876.

29. Chan PS, Caron JP, Orth MW: Effects of glucosamine and chondroitin sulfate on bovine cartilage explants under long-term culture conditions. Am J Vet Res 2007, 68:709-715.

30. Chan PS, Caron JP, Orth MW: Short-term gene expression changes in cartilage explants stimulated with interleukin beta plus glucosamine and 
chondroitin sulfate. J Rheumato/ 2006, 33:1329-1340.

31. Mroz PJ, Silbert JE: Use of $3 \mathrm{H}$-glucosamine and $35 \mathrm{~S}$-sulfate with cultured human chondrocytes to determine the effect of glucosamine concentration on formation of chondroitin sulfate. Arthritis Rheum 2004 50:3574-3579.

32. Biggee $B A$, Blinn CM, McAlindon TE, Nuite M, Silbert JE: Low levels of human serum glucosamine after ingestion of glucosamine sulphate relative to capability for peripheral effectiveness. Ann Rheum Dis 2006, 65:222-226.

33. Chiusaroli R, Natali C, Colombo F, Ballanti P, Rovati LC, Caselli G: Glucosamine sulfate delays progression of spontaneous osteoarthritis in the STR/ORT mouse model. Osteoarthritis Cartilage 2007, 15:C227 (abstract 419).

34. Wen ZH, Tang CC, Chang YC, Huang SY, Hsieh SP, Lee CH, Huang GS, Ng HF, Neoh CA, Hsieh CS, Chen WF, Jean YH: Glucosamine sulfate reduces experimental osteoarthritis and nociception in rats: association with changes of mitogen-activated protein kinase in chondrocytes. Osteoarthritis Cartilage 2010, 18:1192-1202.

35. Ivanovska N, Dimitrova P: Bone resorption and remodeling in murine collagenase-induced osteoarthritis after administration of glucosamine. Arthritis Res Ther 2011, 13:R44

36. Naito K, Watari T, Furuhata A, Yomogida S, Sakamoto K, Kurosawa H, Kaneko K, Nagaoka I: Evaluation of the effect of glucosamine on an experimental rat osteoarthritis model. Life Sci 2010, 86:538-543.

37. Meulyzer M, Vachon P, Beaudry F, Vinardell T, Richard H, Beauchamp G Laverty S: Joint inflammation increases glucosamine levels attained in synovial fluid following oral administration of glucosamine hydrochloride. Osteoarthritis Cartilage 2009, 17:228-234.

38. Meulyzer M, Vachon P, Beaudry F, Vinardell T, Richard H, Beauchamp G, Laverty S: Comparison of pharmacokinetics of glucosamine and synovial fluid levels following administration of glucosamine sulphate or glucosamine hydrochloride. Osteoarthritis Cartilage 2008, 16:973-979.

39. McCarthy G, O'Donovan J, Jones B, McAllister H, Seed M, Mooney C: Randomised double-blind, positive-controlled trial to assess the efficacy of glucosamine/chondroitin sulfate for the treatment of dogs with osteoarthritis. Vet J 2007, 174:54-61.

40. Ozkan FU, Ozkan K, Ramadan S, Guven Z: Chondroprotective effect of $\mathrm{N}$-acetylglucosamine and hyaluronate in early stages of osteoarthritis - an experimental study in rabbits. Bull NYU Hosp Jt Dis 2009, 67:352-357.

41. Silva F, Yoshinari N, Castro R, Girão V, Pompeu M, de Andrade Feitosa J, Rocha $\mathrm{F}$ : Combined glucosamine and chondroitin sulfate provides functional and structural benefit in the anterior cruciate ligament transection model. Clin Rheumatol 2009, 28:109-117.

42. Roda A, Sabatini L, Barbieri A, Guardigli M, Locatelli M Violante FS, Rovati LC Persiani S: Development and validation of a sensitive HPLC-ESI-MS/MS method for the direct determination of glucosamine in human plasma. J Chromatogr B Analyt Technol Biomed Life Sci 2006, 844:1 19-126.

43. Zhong S, Zhong D, Chen X: Improved and simplified liquid chromatography/electrospray ionization mass spectrometry method for the analysis of underivatized glucosamine in human plasma. J Chromatogr B Analyt Technol Biomed Life Sci 2007, 854:291-298.

44. Huang TM, Cai L, Yang B, Zhou MX, Shen YF, Duan GL: Liquid chromatography with electrospray ionization mass spectrometry method for the assay of glucosamine sulfate in human plasma: validation and application to a pharmacokinetic study. Biomed Chromatogr 2006, 20:251-256.

45. Pastorini E, Rotini R, Guardigli M, Vecchiotti S, Persiani S, Trisolino G, Antonioli D, Rovati LC, Roda A: Development and validation of a HPLC-ES-MS/MS method for the determination of glucosamine in human synovial fluid. J Pharm Biomed Anal 2009, 50:1009-1014.

46. Persiani S, Roda E, Rovati LC, Locatelli M, Giacovelli G, Roda A: Glucosamine oral bioavailability and plasma pharmacokinetics after increasing doses of crystalline glucosamine sulfate in man. Osteoarthritis Cartilage 2005, 13:1041-1049.

47. Persiani S, Rotini R, Trisolino G, Rovati LC, Locatelli M, Paganini D, Antonioli D, Roda A: Synovial and plasma glucosamine concentrations in osteoarthritic patients following oral crystalline glucosamine sulphate at therapeutic dose. Osteoarthritis Cartilage 2007, 15:764-772

48. Setnikar I, Rovati LC: Absorption, distribution, metabolism and excretion of glucosamine sulfate. A review. Arzneimittelforschung 2001, 51:699-725.

49. Persiani S, Matthews A, Larger P, Hall M, Rotini R, Trisolino G, Antonioli D, Zaccarelli L, Rovati LC: Glucosamine binding to proteins in plasma and synovial fluid and blood cell/plasma partitioning in mouse and man in vitro. Drug Metabol Drug Interact 2009, 24:211-227.

50. Jackson CG, Plaas AH, Sandy JD, Hua C, Kim-Rolands S, Barnhill JG, Harris CL, Clegg DO: The human pharmacokinetics of oral ingestion of glucosamine and chondroitin sulfate taken separately or in combination. Osteoarthritis Cartilage 2010, 18:297-302.

51. Block JA, Oegema TR, Sandy JD, Plaas A: The effects of oral glucosamine on joint health: is a change in research approach needed? Osteoarthritis Cartilage 2010, 18:5-11.

52. McAlindon TE, LaValley MP, Gulin JP, Felson DT: Glucosamine and chondroitin for treatment of osteoarthritis: a systematic quality assessment and meta-analysis. JAMA 2000, 283:1469-1475.

53. Richy F, Bruyere O, Ethgen O, Cucherat M, Henrotin Y, Reginster JY: Structural and symptomatic efficacy of glucosamine and chondroitin in knee osteoarthritis: a comprehensive meta-analysis. Arch Intern Med 2003, 163:1514-1522.

54. Towheed TE, Maxwell L, Anastassiades TP, Shea B, Houpt J, Robinson V, Hochberg MC, Wells G: Glucosamine therapy for treating osteoarthritis. Cochrane Database Syst Rev 2005:CD002946

55. Reginster JY, Deroisy R, Rovati LC, Lee RL, Lejeune E, Bruyere O, Giacovelli G, Henrotin Y, Dacre JE, Gossett C: Long-term effects of glucosamine sulphate on osteoarthritis progression: a randomised, placebo-controlled clinical trial. Lancet 2001, 357:251-256.

56. Pavelka K, Gatterova J, Olejarova M, Machacek S, Giacovelli G, Rovati LC: Glucosamine sulfate use and delay of progression of knee osteoarthritis: a 3-year, randomized, placebo-controlled, double-blind study. Arch Intern Med 2002, 162:2113-2123

57. Vlad SC, LaValley MP, MCAlindon TE, Felson DT: Glucosamine for pain in osteoarthritis: why do trial results differ? Arthritis Rheum 2007 56:2267-2277.

58. Poolsup N, Suthisisang C, Channark P, Kittikulsuth W: Glucosamine long-term treatment and the progression of knee osteoarthritis: systematic review of randomized controlled trials. Ann Pharmacother 2005, 39:1080-1087.

59. Bruyere O, Burlet N, Delmas PD, Rizzoli R, Cooper C, Reginster JY: Evaluation of symptomatic slow-acting drugs in osteoarthritis using the GRADE system. BMC Musculoskelet Disord 2008, 9:165.

60. Wandel S, Juni P, Tendal B, Nuesch E, Villiger PM, Welton NJ, Reichenbach S, Trelle S: Effects of glucosamine, chondroitin, or placebo in patients with osteoarthritis of hip or knee: network meta-analysis. BMJ 2010, 341:C4675.

61. Clegg DO, Reda DJ, Harris CL, Klein MA, O'Dell JR, Hooper MM, Bradley JD, Bingham CO 3rd, Weisman MH, Jackson CG, Lane NE, Cush JJ, Moreland LW, Schumacher HR Jr, Oddis CV, Wolfe F, Molitor JA, Yocum DE, Schnitzer TJ, Furst DE, Sawitzke AD, Shi H, Brandt KD, Moskowitz RW, Williams HJ: Glucosamine, chondroitin sulfate, and the two in combination for painful knee osteoarthritis. N Engl J Med 2006, 354:795-808.

62. Herrero-Beaumont G, Ivorra JA, Del Carmen Trabado M, Blanco FJ, Benito P, Martín-Mola E, Paulino J, Marenco JL, Porto A, Laffon A, Araújo D, Figueroa M, Branco J: Glucosamine sulfate in the treatment of knee osteoarthritis symptoms: a randomized, double-blind, placebo-controlled study using acetaminophen as a side comparator. Arthritis Rheum 2007, 56:555-567.

63. Sawitzke AD, Shi H, Finco MF, Dunlop DD, Bingham CO 3rd, Harris CL, Singer NG, Bradley JD, Silver D, Jackson CG, Lane NE, Oddis CV, Wolfe F, Lisse J, Furst DE, Reda DJ, Moskowitz RW, Williams HJ, Clegg DO: The effect of glucosamine and/or chondroitin sulfate on the progression of knee osteoarthritis: A report from the glucosamine/chondroitin arthritis intervention trial. Arthritis Rheum 2008 58:3183-3191.

64. Rozendaal RM, Uitterlinden EJ, van Osch GJ, Garling EH, Willemsen SP, Ginai AZ, Verhaar JA, Weinans H, Koes BW, Bierma-Zeinstra SM: Effect of glucosamine sulphate on joint space narrowing, pain and function in patients with hip osteoarthritis; subgroup analyses of a randomized controlled trial. Osteoarthritis Cartilage 2009, 17:427-432.

65. Lee Y, Woo J-H, Choi S, Ji J, Song G: Effect of glucosamine or chondroitin sulfate on the osteoarthritis progression: a meta-analysis. Rheumatol Int 2010, 30:357-363

66. Rozendaal RM, Koes BW, van Osch GJ, Uitterlinden EJ Garling EH, Willemsen SP, Ginai AZ, Verhaar JA, Weinans H, Bierma-Zeinstra SM: Effect of glucosamine sulfate on hip osteoarthritis: a randomized trial. Ann Intern Med 2008, 148:268-277.

67. Bruyere O, Pavelka K, Rovati LC, Gatterova J, Giacovelli G, Olejarova M, Deroisy R, Reginster JY: Total joint replacement after glucosamine sulphate treatment in knee osteoarthritis: results of a mean 8-year observation of patients from two previous 3-year, randomised, placebo-controlled trials. 
Osteoarthritis Cartilage 2008, 16:254-260.

68. Sawitzke AD, Shi H, Finco MF, Dunlop DD, Harris CL, Singer NG, Bradley JD, Silver D, Jackson CG, Lane NE, Oddis CV, Wolfe F, Lisse J, Furst DE, Bingham CO, Reda DJ, Moskowitz RW, Williams HJ, Clegg DO: Clinical efficacy and safety of glucosamine, chondroitin sulphate, their combination, celecoxib or placebo taken to treat osteoarthritis of the knee: 2-year results from GAIT. Ann Rheum Dis 2010, 69:1459-1464.

69. Petersen SG, Saxne T, Heinegard D, Hansen M, Holm L, Koskinen S, Stordal C, Christensen H, Aagaard P, Kjaer M: Glucosamine but not ibuprofen alters cartilage turnover in osteoarthritis patients in response to physical training. Osteoarthritis Cartilage 2010, 18:34-40.

70. Adrogue HJ, Madias NE: Sodium and potassium in the pathogenesis of hypertension. N Engl J Med 2007, 356:1966-1978

71. Kurtz TW, Al-Bander HA, Morris RC Jr: "Salt-sensitive" essential hypertension in men. Is the sodium ion alone important? N Eng/ J Med 1987, 317:1043-1048

72. Dostrovsky NR, Towheed TE, Hudson RW, Anastassiades TP: The effect of glucosamine on glucose metabolism in humans: a systematic review of the literature. Osteoarthritis Cartilage 2011, 19:375-380.

73. Pham T, Cornea A, Blick KE, Jenkins A, Scofield RH: Oral glucosamine in doses used to treat osteoarthritis worsens insulin resistance. Am J Med Sci 2007, 333:333-339.

74. Biggee BA, Blinn CM, Nuite M, Silbert JE, MCAlindon TE: Effects of oral glucosamine sulphate on serum glucose and insulin during an oral glucose tolerance test of subjects with osteoarthritis. Ann Rheum Dis 2007, 66:260-262
75. Chien CS, Cheng SC, Wu HT, Tsao CW, Cheng JT: Insulin resistance induced by glucosamine in fructose-fed rats. Horm Metab Res 2009, 41:542-547.

76. Simon RR, Marks V, Leeds AR, Anderson JW: A comprehensive review of oral glucosamine use and effects on glucose metabolism in normal and diabetic individuals. Diabetes Metab Res Rev 2011, 27:14-27.

77. Stumpf JL, Lin SW: Effect of glucosamine on glucose control. Ann Pharmacother 2006, 40:694-698.

78. Dworkin RH, Peirce-Sandner S, Turk DC, McDermott MP, Gibofsky A, Simon LS, Farrar JT, Katz NP: Outcome measures in placebo-controlled trials of osteoarthritis: responsiveness to treatment effects in the REPORT database. Osteoarthritis Cartilage 2011, 19:483-492.

79. Gruenwald J, Petzold E, Busch R, Petzold H-P, Graubaum H-J: Effect of glucosamine sulfate with or without omega-3 fatty acids in patients with osteoarthritis. Adv Ther 2009, 26:858-871.

80. Das A Jr, Hammad TA: Efficacy of a combination of FCHG49 glucosamine hydrochloride, TRH122 low molecular weight sodium chondroitin sulfate and manganese ascorbate in the management of knee osteoarthritis. Osteoarthritis Cartilage 2000, 8:343-350.

81. NICE Clinical Guidelines: The care and management of osteoarthritis in adults [www.nice.org.uk/CG059]

doi:10.1186/ar3657

Cite this article as: Henrotin $Y$, et al.: Is there any scientific evidence for the use of glucosamine in the management of human osteoarthritis? Arthritis Research \& Therapy 2012, 14:201. 